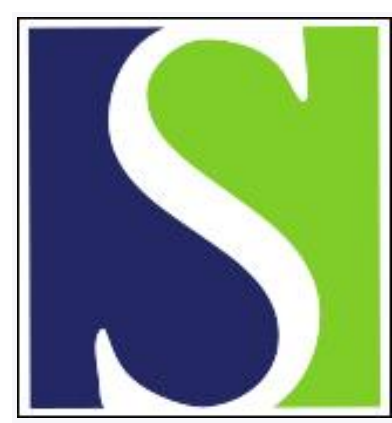

Scand J Work Environ Health 1981;7(3):233-236

https://doi.org/10.5271/sjweh.3116

Issue date: Sep 1981

Disappearance of carbon monoxide from the blood comparison of the one-exponential and two-exponential elimination models for rat

by Kurppa $\mathrm{K}$

Affiliation: Institute of Occupational Health, SF-00290 Helsinki, Finland.

Key terms: blood; carbon monoxide; carboxyhemoglobin; elimination model; one-exponential elimination model; rat; two-exponential elimination model

This article in PubMed: www.ncbi.nlm.nih.gov/pubmed/20120589

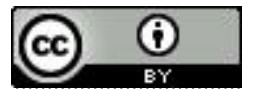




\title{
Disappearance of carbon monoxide from the blood
}

\author{
Comparison of the one-exponential and two-exponential elimination \\ models for rat
}

\author{
by Kari Kurppa, MD ${ }^{1}$
}

\begin{abstract}
KURPPA K. Disappearance of carbon monoxide from the blood: Comparison of the one-exponential and two-exponential elimination models for rat. Scand $j$ work environ health 7 (1981) 233-236. The elimination of carbon monoxide from rat blood was studied from a starting point of a nonsteady-state concentration of $40 \%$ for carboxyhemoglobin $(\mathrm{COHb})$. The accuracy of the fit was statistically improved by the employment of a two-exponential elimination model rather than that of the one-exponential model. Yet, the differences in the COHb estimates attained with the two models were negligible. Therefore, for practical purposes, the one-exponential model seems reasonably reliable for estimating $\mathrm{COHb}$.
\end{abstract}

Key terms: carboxyhemoglobin.

Most earlier studies have concluded that carbon monoxide $(\mathrm{CO})$ is eliminated at a constant exponential rate. This conclusion means that there is a stable half-time for carboxyhemoglobin ( $\mathrm{COHb})(1,4,5,9$, $10,13)$. The half-time concept is convenient for practical purposes. However, a biphasic decline in the concentration of $\mathrm{COHb}$ has recently been reported after nonsteady-state exposure conditions $(3,8$, 14). An initial rapid disappearance of $\mathrm{COHb}$ followed by a slower CO elimination seems possible. This observation is interesting since it may have practical importance in the calculation of the postexposure body burdens of $\mathrm{CO}$. It might challenge the applicability of the current practice of using a single $\mathrm{COHb}$ half-time for estimation purposes. Therefore, it was of interest to study the extent to which

1 Department of Epidemiology and Biometry, Institute of Occupational Health, Helsinki, Finland.

Reprint requests to: Dr $\mathrm{K}$ Kurppa, Institute of Occupational Health, Haartmaninkatu 1, SF-00290 Helsinki, Finland. the estimates of $\mathrm{COHb}$ by the one-exponential and two-exponential elimination models actually deviate from each other.

\section{Animals and methods}

Nineteen male Wistar rats $(294 \pm 29 \mathrm{~g}$, mean $\pm \mathrm{SD}$ ) were exposed to $1,000 \mathrm{ppm}$ of $\mathrm{CO}$ for $22 \mathrm{~min}$. The steady-state $\mathrm{COHb}$ concentration is approximately $60 \%$ at this exposure level, and it is reached in about $1.5 \mathrm{~h}(7,11)$. The exposure took place in a dynamic exposure chamber of $1 \mathrm{~m}^{3}$ equipped with an infrared analyzer for the measurement and control of $\mathrm{CO}$ concentration (Miran 1A, Wilks Scientific Corp). The rats were decapitated and bled into heparinized glass tubes.

The concentrations of $\mathrm{COHb}$ were determined by gas chromatography (2). The coefficient of variation was about $3 \%$ (rel) at the $\mathrm{COHb}$ level of $30 \%$ (nine determinations). The mean endogenous $\mathrm{COHb}$ of the rats $(0.4 \pm 0.1 \%$, mean \pm $\mathrm{SD)}$ was calculated from the blood samples of 15 nonexposed animals.

Parameter values for the $\mathrm{CO}$ elimination 
models were optimized by the Marquardt's nonlinear least squares iteration method (6, 12). A Tektronix 4052 minicomputer was used for the calculations. In order to ensure the best solutions, several starting values were tried for the parameters.

The average endogenous $\mathrm{COHb}$ concentration of $0.4 \%$ was inserted in the models

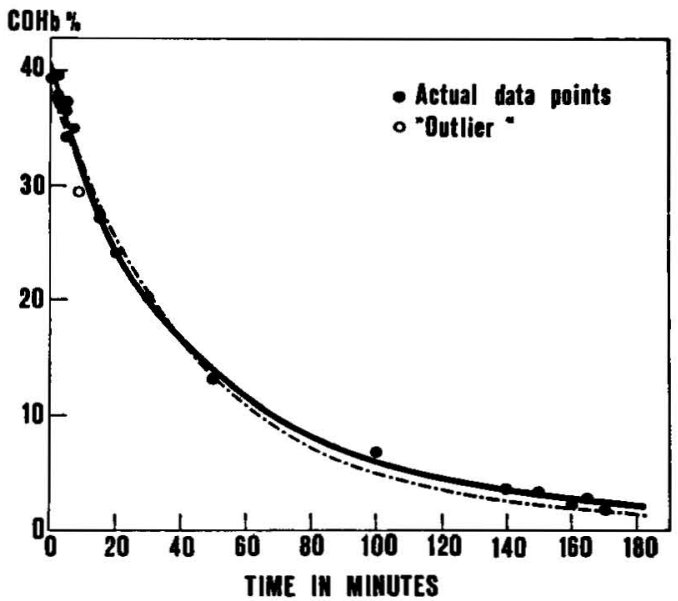

Fig 1. The carboxyhemoglobin (COHb) elimination curves of the one-exponential (broken line) and two-exponential (solid line) elimination models. as an asymptote. The equation for the one-exponential model followed the formula

$$
\mathrm{COHb}_{\mathrm{t}}=\left(\mathrm{COHb}_{0}-0.4\right) \mathrm{e}^{-\mathrm{bt}}+0.4 \text {, }
$$

where $\mathrm{COHb}_{0}$ denotes the actually measured concentration of $\mathrm{COHb}$ at the beginning of the elimination process and $\mathrm{COHb}_{\mathrm{t}}$ the actual concentration of $\mathrm{COHb}$ at time t. The two-exponential model was described by the formula

$$
\mathrm{COHb}_{\mathrm{t}}=\mathrm{a} \mathrm{e}^{-\mathrm{bt}}+\mathrm{ce}^{-\mathrm{dt}}+0.4
$$

where $\mathrm{a}+\mathrm{c}=\mathrm{COHb}_{0}-0.4$, symbols $\mathrm{b}$ and $\mathrm{d}$ denoting rate constants.

Fits for the elimination models were first computed from the crude data, ie, all of the $\mathrm{COHb}$ results were used. $\mathrm{COHb}$ values that deviated more than two standard deviations from the respective estimates simultaneously in both elimination models were deleted from the final analyses. One such data point $(9 \mathrm{~min}, 29.6 \%$ $\mathrm{COHb}$ ) was found. (The result of the statistical comparison remains essentially similar with or without the deletion of the "outlier.")

Table 1. The optimized parameters of the carboxyhemoglobin $(\mathrm{COHb})$ elimination models by the

\begin{tabular}{|c|c|c|c|}
\hline Model & \multicolumn{2}{|c|}{ Parameter } & SE \\
\hline $\begin{array}{l}\text { One-exponential } \\
y=a e^{-b t}+0.4\end{array}$ & $\begin{array}{l}\text { a }[\% \mathrm{COHb}] \\
\text { b }\left[\mathrm{min}^{-1}\right]\end{array}$ & $\begin{array}{l}38.6 \\
0.022\end{array}$ & $\begin{array}{l}0.4 \\
0.001\end{array}$ \\
\hline $\begin{array}{l}\text { Two-exponential } \\
y=a e^{-b t}+c e^{-d t}+0.4\end{array}$ & $\begin{array}{l}\text { a }[\% \mathrm{COHb}] \\
\text { b }\left[\mathrm{min}^{-1}\right] \\
\text { c }\left[\% \mathrm{COH}^{0} \mathrm{Hb}\right] \\
\text { d }\left[\mathrm{min}^{-1}\right]\end{array}$ & $\begin{array}{l}13.8 \\
0.05 \\
25.6 \\
0.016\end{array}$ & $\begin{array}{l}7.5 \\
0.02 \\
7.6 \\
0.002\end{array}$ \\
\hline
\end{tabular}
Marquardt's least squares iteration method.a

a $y=\mathrm{COHb}_{\mathrm{t}}(\%)$, e = base of natural logarithms, $t=$ time in minutes, $\mathrm{SE}=$ parameter standard error.

Table 2. Comparison of the accuracy of the one-exponential and two-exponential elimination models by the $F$ test of variances with a one-sided risk level.a

\begin{tabular}{lcccc}
\hline Model & $\begin{array}{c}\text { Sum of } \\
\text { squares }\end{array}$ & df & F & p \\
\hline One-exponential & 12.8 & 16 & $\overline{14.4}$ & $-\overline{0.0005}$ \\
Two-exponential & 4.4 & 14 & 14 & \\
\hline
\end{tabular}

a $\mathrm{df}=$ degrees of freedom; $F=[(12.8-4.4) / 2] /(4.4 / 14)=14.4$. 
The mathematical accuracy between the $\mathrm{COHb}$ data and the respective estimates by the elimination models was compared by the $F$ test of variances.

\section{Results}

Table 1 presents the optimized parameters of the elimination models. The two-exponential model showed relatively large parameter errors.

The elimination curves of the one-exponential and the two-exponential models are visualized in fig 1 . The curves intercepted twice but did not deviate far from each other. The one-exponential curve was slightly inaccurate at both ends of the $\mathrm{COHb}$ data.

The application of the two-exponential model, instead of the one-exponential model, statistically improved the mathematical accuracy of the fit (table 2).

\section{Discussion}

The accuracy of the two-exponential model was statistically superior to that of the one-exponential model. Thus, it appears that the elimination process of $\mathrm{CO}$ from the blood may be more complex than that described by a one-exponential model (half-time of about $32 \mathrm{~min}$ for $\mathrm{COHb}$ ). This observation is interesting with respect to the theory of the kinetics of $\mathrm{CO}$ in the body.

The $\mathrm{COHb}$ estimates of the two elimination models studied do not differ much, despite the statistically significant improvement of the accuracy attained with the two-exponential model. The increase in the accuracy of the fit seems negligible for practical purposes. For instance, with a hypothetical $\mathrm{COHb}$ value of $40 \%$ as a starting point, the one-exponential model predicts a $\mathrm{COHb}$ concentration of $25.9 \%$ after $20 \mathrm{~min}$, while the two-exponential model yields an estimate of $24.2 \%$ at the same time point. After $180 \mathrm{~min}$ from the start of the elimination, the $\mathrm{COHb}$ estimates of the one-exponential and two-exponential models would be 1.2 and $1.8 \%$, respectively.

The two-exponential model seems too complex to be prudently fitted with the present number of observations since the parameter errors become unreasonably large. Obviously, at least a couple of hundred observations would be needed in order to achieve error limits comparable to those of the one-exponential model.

In conclusion, the accuracy of the fit in the simulation of $\mathrm{COHb}$ disappearance is statistically improved with the use of the two-exponential model instead of the oneexponential model. The practical significance of this improvement seems negligible, however.

\section{Acknowledgments}

I am grateful to Prof K Kalliomäki, Mr E Järvinen, and $\mathrm{Dr} \mathrm{H}$ Savolainen for their mathematical advice and to Ms $\mathrm{H}$ Roos, Ms $T$ Korhonen, and Ms $H$ Kivistö for their technical assistance.

\section{References}

1. Coburn RF, Forster RE, Kane PB. Considerations of the physiological variables that determine the blood carboxyhemoglobin concentration in man. $\mathrm{J}$ clin invest 44 (1965) $1899-1910$.

2. Collison HA, Rodkey FL, O'Neal JD. Determination of carbon monoxide in blood by gas chromatography. Clin chem 14 (1968) 162-171.

3. Godin G, Shephard RJ. On the course of carbon monoxide uptake and release. Respiration 29 (1972) 317-329.

4. Goldsmith JR, Terzaghi J, Hackney JD. Evaluation of fluctuating carbon monoxide exposures. Arch environ health 7 (1963) $647-663$.

5. Hackney JD, Kaufman GA, Lashier H, Lynn $\mathrm{K}$. Rebreathing estimate of carbon monoxide hemoglobin. Arch environ health 5 (1962) $300-307$.

6. Marquardt DW. An algorithm for leastsquares estimation of non-linear parameters. J soc ind appl math 2 (1963) 431-441.

7. Montgomery MR, Rubin RJ. The effect of carbon monoxide inhalation on in vivo drug metabolism in the rat. $J$ pharmacol exp ther 179 (1971) 465-473.

8. Myhre L. Rate of $\mathrm{CO}$ elimination in resting man. Fed proc 33 (1974) 440 (abstract).

9. Pace N, Strajman E, Walker EL. Acceleration of carbon monoxide elimination in man by high pressure oxygen. Science 111 (1950) 652-654.

10. Peterson JE, Stewart RD. Absorption and 
elimination of carbon monoxide by inactive young men. Arch environ health 21 (1970) 165-171.

11. Savolainen $\mathrm{H}$, Kurppa $\mathrm{K}$, Tenhunen R, Kivistö $H$. Biochemical effects of carbon monoxide poisoning in rat brain with special reference to blood carboxyhemoglobin and cerebral cytochrome oxidase activity. Neuro sci lett 19 (1980) 319-323.

12. Tektronix Inc. Tektronix plot $50,4050 \mathrm{~A} 10$.

Received for publication: 7 May 1981
Statistics vol 4. Beaverton, OR 1977.

13. Tobias CA, Lawrence JH, Roughton FJW, Root WS, Gregersen MI. The elimination of carbon monoxide from the human body with reference to the possible conversion of $\mathrm{CO}$ to $\mathrm{CO}_{2}$. Am $\mathrm{j}$ physiol 145 (1945) 253-263.

14. Wagner JA, Horvath SM, Dahms TE. Carbon monoxide elimination. Resp physiol 23 (1975) $41-47$. 